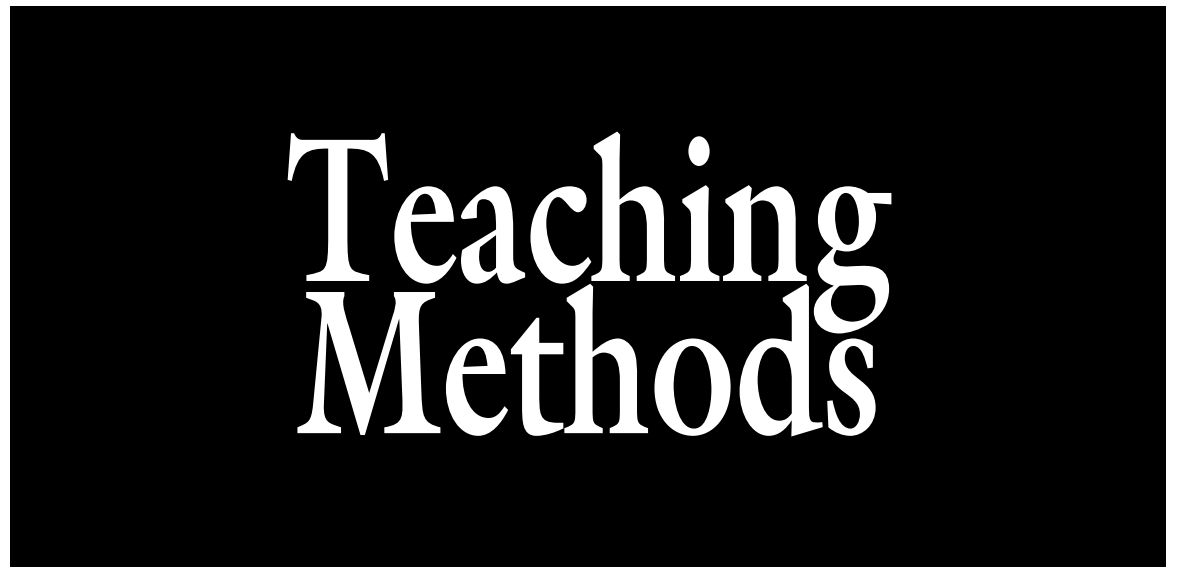

\section{A Survey of North American Horticulture Graduate Programs: Demographics, Policies, Finances, and Metrics}

\author{
Michael A. Arnold ${ }^{1,6}$, R. Daniel Lineberger ${ }^{2}$, Tim D. Davis ${ }^{3}$, \\ David W. Reed ${ }^{4}$, and William J. McKinley ${ }^{5}$
}

ADDITIONAL INDEX WORDs. assessment, faculty compensation, faculty demographics, graduate admissions, graduate student compensation, graduate student demographics, graduate student training, peer institution comparisons

Summary. A comprehensive survey of American and Canadian universities that offer masters, doctoral, or both degrees in horticulture resulted in responses from 27 academic units. Units were surveyed regarding types of degrees offered, admissions policies, demographic characteristics of students, financial assistance provided to students, faculty ranks and salaries, and metrics by which the programs were evaluated by university administration. About $80 \%$ of the programs resided in 1862 Morrill Act land-grant institutions (LG) with the remainder housed in other non-land-grant institutions (NLG). Thirty-eight percent of reporting LG programs existed as stand-alone horticulture departments, whereas horticulture programs were combined with other disciplines in the remainder. Admissions criteria were most consistent among LG programs. Participation in distance education programs was low, but growing. Financial support of graduate students was more common in LG programs. Most schools offered some sort of tuition reduction to those students on assistantships/ fellowships and offered health insurance options. Payment of fees was rare and the level of stipends provided varied substantially among programs. International student enrollment was greatest at LG programs and had remained steady in recent years. Gender equity was present among graduate students, with nearly equal male and female enrollment. Most graduate students at both LG $(63.6 \%)$ and NLG (75.0\%) programs were non-Hispanic White; although overall minority enrollment had increased but was still not similar in distribution to that of the general U.S. population. Professors (46.7\%) and Associate Professors (28.3\%) dominated the faculty ranks while Assistant Professors (19.3\%) and lecturers/ instructors $(5.7 \%)$ constituted a much smaller portion of the faculty. Faculty salaries varied tremendously among institutions, especially for senior faculty. Female and ethnic minorities were underrepresented in faculty ranks compared with the general U.S. population. Aside from total graduate program enrollment, the relative importance of various evaluation metrics for programs was highly variable among institutions. Data discussed herein should be useful to universities with horticulture graduate programs for peer institution comparisons during program assessments, accreditation reviews, or for strategic planning purposes.

$\mathrm{P}$ eriodic review of academic programs is important for maintaining programmatic standards and comparing progress of programs relative to their peer institutions. Information on research productivity and some faculty metrics are available from various databases (Academic Analytics, 2013; Marchant et al., 2010; U.S. Department of Education, 2014). One challenge with these databases is that different institutions for a variety of reasons code similar degrees or professions under different classification of instructional programs [CIP codes (U.S. Department of Education, 2014)], which complicates accurate extraction of data for degree programs that cut across different CIP codes. For instance, just the CIP codes associated with nursery and greenhouse manager occupation titles are listed under several codes, including general agricultural business and management (01.0101), agribusiness/agricultural business operations (01.0102), ornamental horticulture (01.0603), greenhouse operations and management (01.1105), plant nursery operation and management (01.0606), horticultural sciences (01.1103), and plant protection and integrated pest management (01.1105). Even when research productivity and faculty demographics are compiled and extracted, quantitative information on programmatic effectiveness, program policies, program assessment, and student demographics are often less readily accessible.

Much information and assistance is available for conducting assessment programs and analyzing assessment data internally in general terms (Astin and Antonio, 2012) and to a more limited extent specifically for internal assessment of undergraduate horticulture programs (Duncan et al., 2008; Rom, 2004). External assessment data from industry and former students can also be useful in evaluating programmatic effectiveness (Beidler et al., 2006; Madewell et al., 2003; VanDerZanden and Reinert, 2009). External accreditation reviews are similar to internal assessment programs, but differ in that the emphasis of an accreditation review is on the education process rather than its outcomes (Nichols and Nichols, $2000)$. One challenge of preparing for an external accreditation review is the need for comparative data from peer programs, not only on demographics but also on policy issues. Specific information (Arnold et al., 2006) on the programmatic processes, admissions criteria, demographics, finances and metrics of evaluation of horticulture graduate programs is limited. Previous 
work (Arnold et al., 2006) found that racial/ethnic populations in horticulture graduate programs did not reflect the U.S. population as a whole, but no information was provided on trends or on racial/ethnic populations in the horticulture faculty ranks. Data from this work also indicated that graduate student and faculty salaries at NLG horticulture graduate programs lagged behind those at LG programs. Davies (2005) expressed concerns about a lack of teaching experience or training in LG horticulture graduate programs. Darnell and Cheek (2005) expressed concerns about the transfer of assistantship costs from institutional support to faculty-derived funds causing shifts of resource allocations from graduate assistantships to technicians or postdoctoral positions.

The purpose of this work was to gather information on programmatic processes, admissions criteria, demographics, finances, and metrics of evaluation specific to horticulture graduate programs, which might then be used for peer institution comparisons during program assessments, accreditation reviews, or for contextual background for strategic planning. Goals of this effort were to determine student demographics with regard to similar programs on a national basis, determine how a variety of programmatic requirements and procedures were used at each institution, determine the types of graduate programs and support provided to students by the various departments, determine how departments were financing students and what types of training they were providing, and to document demographics associated with the faculty at peer institutions. Also, these

\footnotetext{
Department of Horticultural Sciences, Texas A\&M University, College Station, TX 77843-2133

Mention of a trademark, proprietary product, or vendor does not constitute a guarantee or warranty of the product by the authors, the Texas A\&M University, or Texas A\&M AgriLife Research and does not imply its approval to the exclusion of other products or vendors that also may be suitable. The cost of publishing this paper was defrayed in part by the payment of page charges. Under postal regulations, this paper therefore must be hereby marked advertisement solely to indicate this fact.

${ }^{1}$ Professor and Associate Head for Undergraduate Programs

${ }^{2}$ Professor and Department Head

${ }^{3}$ Professor and Regional Director for Asia in Borlaug Institute for International Agriculture

${ }^{4}$ Professor and Associate Dean

${ }^{5}$ Senior Lecturer and Benz Chair of Floral Design

${ }^{6}$ Corresponding author. E-mail: ma-arnold@tamu.edu.
}

results would allow comparisons with previous data obtained in a 2005 survey of similar institutions (Arnold et al., 2006) to determine the extent of changes and identify potential trends likely as part of broader scale developments.

\section{Materials and methods}

On 11 Oct. 2012, a survey was submitted to U.S. and Canadian universities that offer graduate degree programs with majors in horticulture or concentrations in horticulture within broader based related agriculture or plant science majors. The 54 programs included in the previous horticulture graduate program survey conducted from Dec. 2004 to Feb. 2005 (Arnold et al., 2006) constituted the initial list of potential participants for this survey. Another overlapping group included those institutions in the horticultural data portion (25 units) of the Academic Analytics database (Academic Analytics, 2013). Additionally, the survey instrument was sent to list-serves of the administrators and teaching working groups of the American Society for Horticultural Science. Follow-up letters/reminders were sent at 1 -month intervals for 3 months following the original release of the survey. Twentytwo 1862 Morrill Act LG, one Canadian university, and four state-supported NLG responded to the survey (Table 1 ). A fifth state-supported NLG also responded to indicate that their masters program was currently inactive. In addition to the LG and NLG, several 1890 LG were also included in the survey, but none responded. Based on the original 54 programs contacted, this constituted a $50 \%$ response rate, with $48 \%$ useable responses. This represents an acceptable to good level of response to e-mail/ electronic surveys for teaching assessment purposes (University of Texas at Austin, 2011).

In addition to reported actual dollars, cost of living adjusted (COLA) dollars were also calculated to compare salaries to the national average cost of living as indicated by the Economics Research Institute database (Economics Research Institute, 2013). The COLA dollars were based on the ratios provided for the cities in which the institution resided. If the national average had a cost of living of $\$ 1000$, then the highest cost of living at reporting institutions was $\$ 1334$ and the lowest was $\$ 868$, yielding a $46.6 \%$ deviation from the national average between the highest and lowest participating locations. Costs of living varied for the cities of residence for participating LG, from $86.8 \%$ of the national average in College Station, $\mathrm{TX}$, to $133.4 \%$ of the national average in Ithaca, NY. A notation of COLA is used to indicate adjusted financial data; if no notation is indicated, values represent actual reported dollar amounts.

\section{Results and discussion}

CHARACT ERIZATION OF HORTICULTURE DEGREE OR CONCENTRATION PROGRAMS. Among LG, 36\% of horticulture graduate programs were in stand-alone horticulture departments and $50 \%$ were in blended units with one or more related disciplines, such as horticulture and crops science or horticulture and landscape architecture. Only 14\% were in general plant science departments and none were in general agriculture or life sciences units. In contrast, horticulture programs at NLG were all housed in either general plant science departments or general agriculture/ life sciences units. The number of programs offering horticulture-oriented graduate degrees at LG was similar to that reported in 2005 (Arnold et al., 2006), although considerably fewer NLG responded to the current survey ( 5 vs. 13 previously).

Doctor of philosophy (Ph.D.) programs were about evenly split between those with a horticulture major and those with concentrations in horticulture within a broader plant science major (Table 2). However, students in the typical plant science program were about twice that of horticulture-only programs and plant science was the only option offered in NLG Ph.D. programs. Slightly more master of science (M.S.) thesis and non-thesis programs had horticulture-only majors than those present as concentrations within plant science M.S. programs. Although, as with the Ph.D. programs, about twice as many students were enrolled in plant science than horticulture majors (Table 2).

Compared with 2005, enrollment in LG programs in horticulture at both the Ph.D. and masters levels were similar to current levels, but enrollment in a horticultural emphasis 
Table 1. Participating institutions responding to an electronic mail survey to characterize various aspects of demographics, policies, finances, and metrics of horticulture graduate programs which was conducted in Oct. 2012 of land-grant and nonland-grant universities that offered horticulture related graduate degrees in North America.

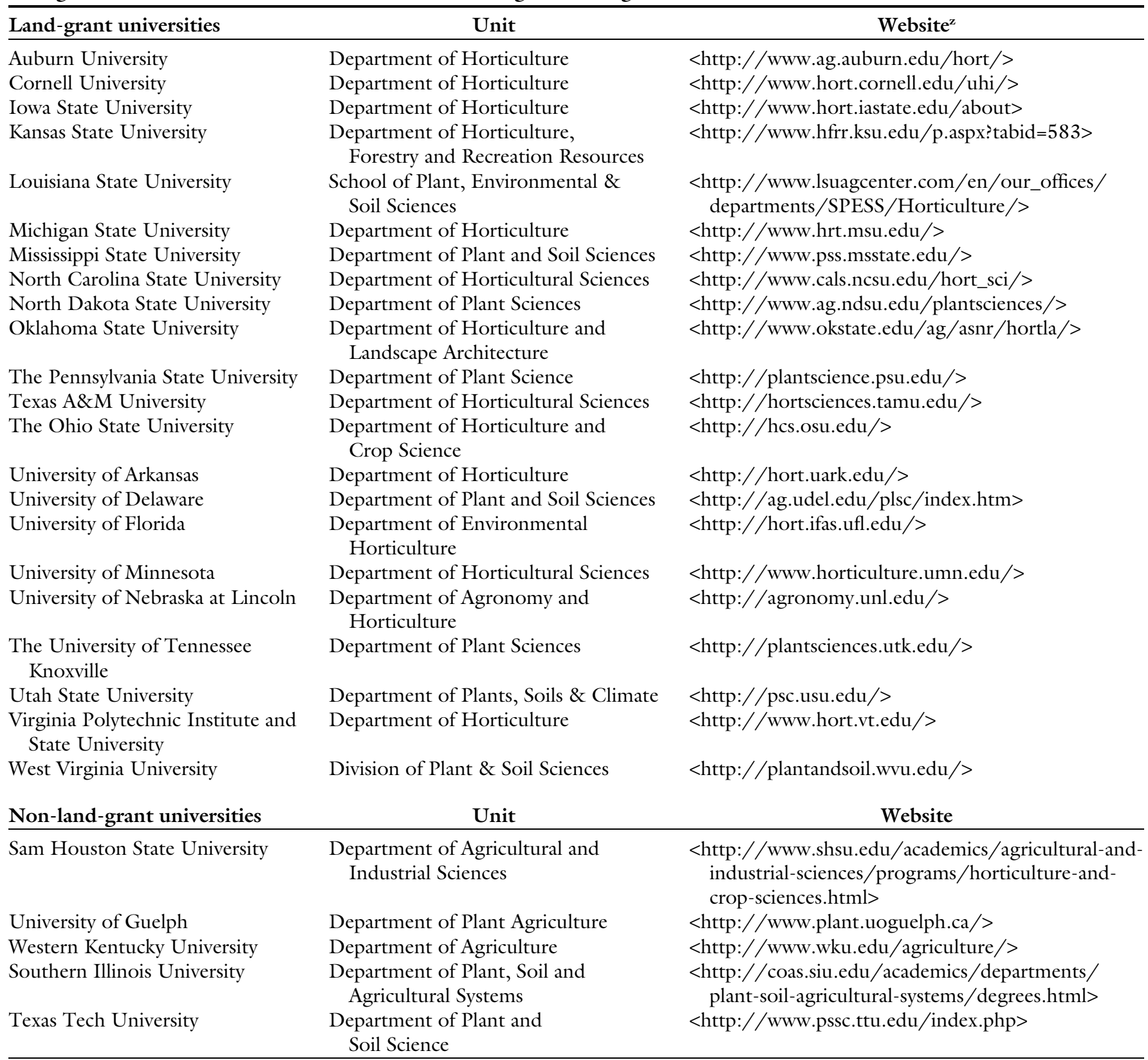

${ }^{\mathrm{z}}$ All websites were last accessed on $26 \mathrm{Feb} .2014$.

in the more generalized plant science programs has increased (Arnold et al., 2006). Although the proportions are still small, the enrollment in non-thesis horticulture masters programs has increased compared with 2005 levels (Arnold et al., 2006). When "other" was listed (Table 2), it was frequently mentioned as either non-degree seeking students or those in some sort of postgraduate certificate program. Enrollment in horticulture or plant science degree programs with a horticultural emphasis at NLG graduate programs (Table 2) were less than that reported in 2005 (Arnold et al., 2006)

No responding institutions offered a distance Ph.D. program in horticulture or in a plant science program with a horticulture concentration. Six masters-level programs in horticulture or in plant science with a horticulture emphasis were offered by distance education: four by LG and two by NLG. Only one institution offered a thesis option M.S. in plant science with a horticultural emphasis at a distance, all other available masters programs were non-thesis degrees.

Participation in distance courses within in-residence programs was still uncommon, but appeared to be a growing course option compared with the previous horticulture graduate program survey (Arnold et al., 2006). Across in-residence graduate degree programs, participation in courses offered at a distance average from $10.7 \%$ for non-thesis masters programs to $16.5 \%$ of thesis requiring masters programs. This was an increase compared 
Table 2. Doctor of philosophy (Ph.D.) and masters degrees offered in-residence by units offering either degree programs with a horticulture major or those with a more generalized plant science-type major with some type of specialization in horticulture as reported in an Oct. 2012 electronic mail survey.

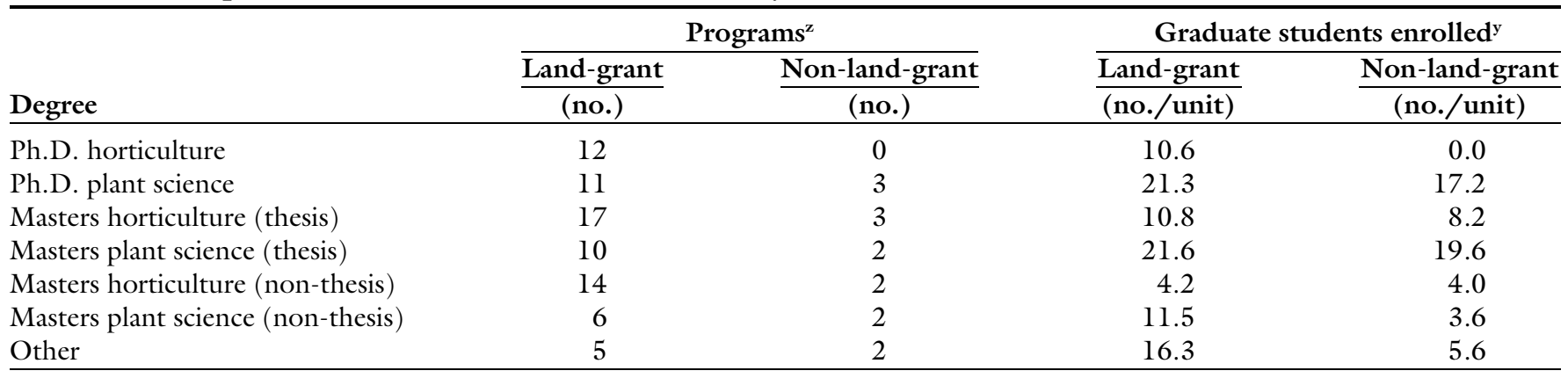

${ }^{2}$ Number of programs indicating they offered this type of program are indicated in these columns.

${ }^{y}$ Mean number of students reported enrolled in that particular degree program are indicated in these columns.

with $4.1 \%$ to $4.5 \%$ participation in distance courses by in-residence students in 2005 (Arnold et al., 2006).

More than half of both LG $(57.1 \%)$ and NLG (66.7\%) units permitted direct admission to Ph.D. programs without a prior M.S. degree. No schools reported using a laboratory rotation system during admissions procedures, which sometimes is used in more basic science programs, for either LG or NLG horticulture graduate programs. This is likely because all (100\%) of the LG programs required the identification of a faculty member willing to serve as the student's advisor before admitting the student to the program, a process that would likely be incompatible with a laboratory rotation program. This represents a change in policy at some institutions as in 2005 only $84.1 \%$ of the institutions required an advisor at admissions and $15.9 \%$ permitted some form of laboratory rotation (Arnold et al., 2006). A majority (60.0\%) of NLG also required that a faculty advisor be identified before admitting the student. A majority (60.0\%) of NLG indicated other admissions criteria, such as documentation of adequate support. Admissions criteria were fairly consistent across programs with $100 \%$ of both NLG and LG including prior grade point averages or ratios in the process. All (100\%) programs included an English language proficiency measure for international students whose native language was not English. Recommendation letters were required by $100 \%$ of LG programs and $80.0 \%$ of NLG. Although the effectiveness of Graduate Record Examinations (GRE) scores in predicting the effectiveness of graduate students in various programs of study has long been debated (Oltman and Hartnett, 1984), nearly all (95.5\%) LG considered GRE scores in the admissions process. A majority (60.0\%) of NLG also incorporated GRE scores in the matrix of admissions criteria. Interestingly, none of the responding institutions reported any specialized entrance examinations beyond the GRE, perhaps due to the lack of available standardized specialized entrance examinations for the horticulture field. Several (40.9\%) LG indicated other criteria were also involved in the admissions process with an essay or statement of purpose being the most frequently cited measure. No additional criteria were indicated by NLG.

DEMOGRAPHICS OF STUDENTS IN HORTICULTURE GRADUATE DEGREE OR CONCENTRATION PROgRAMs. Domestic students constituted the majority of the enrollment in both LG and NLG programs, but domestic students $(65.2 \%)$ were a smaller majority of the population than in NLG programs (80.6\%) with international students making up 34.8\% of the LG horticulture graduate students on average vs. only $19.4 \%$ at NLG. Interestingly, the proportion of domestic vs. international students has remained nearly unchanged since the 2005 survey (Arnold et al., 2006) and was similar to that reported by Darnell and Cheek (2005) from their 2004 data on plant science degree programs; although the proportion of international students was highly variable in the present survey ranging from $0 \%$ to $58 \%$ of the students among all programs. The largest ethnic population of students in the survey (across all international and domestic students) was nonHispanic Whites (Caucasian) at both LG (63.6\%) and NLG (75.0\%) programs. Compared with the 2005 survey, non-Hispanic White enrollment has dropped as a percentage of the total enrollment at LG from $69.1 \%$, but increased slightly from 72.9\% at NLG (Arnold et al., 2006). The second largest ethnic/racial group at LG (14.0\%) was Asian (other than Indian/Pakistani) and was tied for second most populous in NLG at 9.0\%. At NLG, Indian/Pakistani student enrollment $(9.0 \%)$ was tied for second, but this group comprised only $4.9 \%$ of students at LG. Total Asian and Indian/Pakistani ethnic student enrollment has increased compared with the 2005 survey in both NLG and LG (Arnold et al., 2006). At LG, the third most frequent ethnic/racial group was Hispanics (6.9\%) while this was only the sixth largest group at NLG (1.3\%). Compared with the 2005 survey, Hispanic enrollment has nearly doubled at LG, but remained the same at NLG (Arnold et al., 2006). Interestingly, Marchant et al. (2010) report a different rank order among doctoral degrees awarded to minority students in all agricultural program areas, with Asian students receiving the most, followed by Hispanic, Black, unspecified minority, and then Native American and Native Hawaiian in the Food and Agricultural Education Information System database (Food and Agricultural Education Information System, 2014). In this study, black students represented $3.0 \%$ of students at LG and $2.3 \%$ of students in NLG degree programs. Black enrollment at LG horticulture programs has remained steady since 2005 (3.0\% vs. 2.5\%), while that at NLG $(2.3 \%$ vs. $8.0 \%)$ has declined substantially (Arnold et al., 2006). This apparent decline in black 
enrollment at NLG may be because none of the 1890 amended Morrill Act LG responded to this survey (Table 1), whereas several did respond to the 2005 survey (Arnold et al., 2006). Native American enrollment was small in both groups, but greater $(2.5 \%)$ in NLG than in LG $(0.3 \%)$ programs. Native American enrollment has increased from nearly none at either type of institution in the 2005 survey (Arnold et al., 2006). The ethnic/racial category of "other" was not reported for NLG, while it constituted $6.1 \%$ of the reported enrollment at LG programs. "Other" was often noted to include those indicating no racial or ethnicity group or to include international students if they were not included in one of the other reported groups. Students of Arab or Middle Eastern descent were also a group noted under "other" by some institutions.

FINANCIAL SUPPORT OF STUDENTS IN HORTICULTURE GRADUATE DEGREE OR CONCENTRATION PROGRAMS. At LG, an average of $83.1 \%$ of graduate students received institutional support, whereas at NLG, only $66.1 \%$ of graduate students were funded (Table 3 ). The largest single funding source for students was research assistantships, particularly at LG (Table 3). Research assistantships increased substantially as a proportion of the source of funding for graduate assistantships for both types of institutions since the 2005 survey (Arnold et al., 2006). Research assistantships were often mentioned by participants as funded by external grants obtained by the faculty rather than internal institutional dollars. The second largest source of funding for graduate students was teaching assistantships for NLG (Table 3). While teaching-only assistantships constituted a smaller proportion of funding sources for graduate students at LG, when merged with combined responsibility assistantships, the proportionate funding source $(17.0 \%)$ was similar to that of teaching assistantships at NLG (17.4\%). Although a relatively small proportion of the overall funding, fellowships were about twice as much of the funding sources at LG than at NLG (Table 3). On average, both LG and NLG had about 5\% of the horticulture graduate students funded by their home (non-U.S./ Canadian) country (Table 3 ). The proportion of nonfunded students

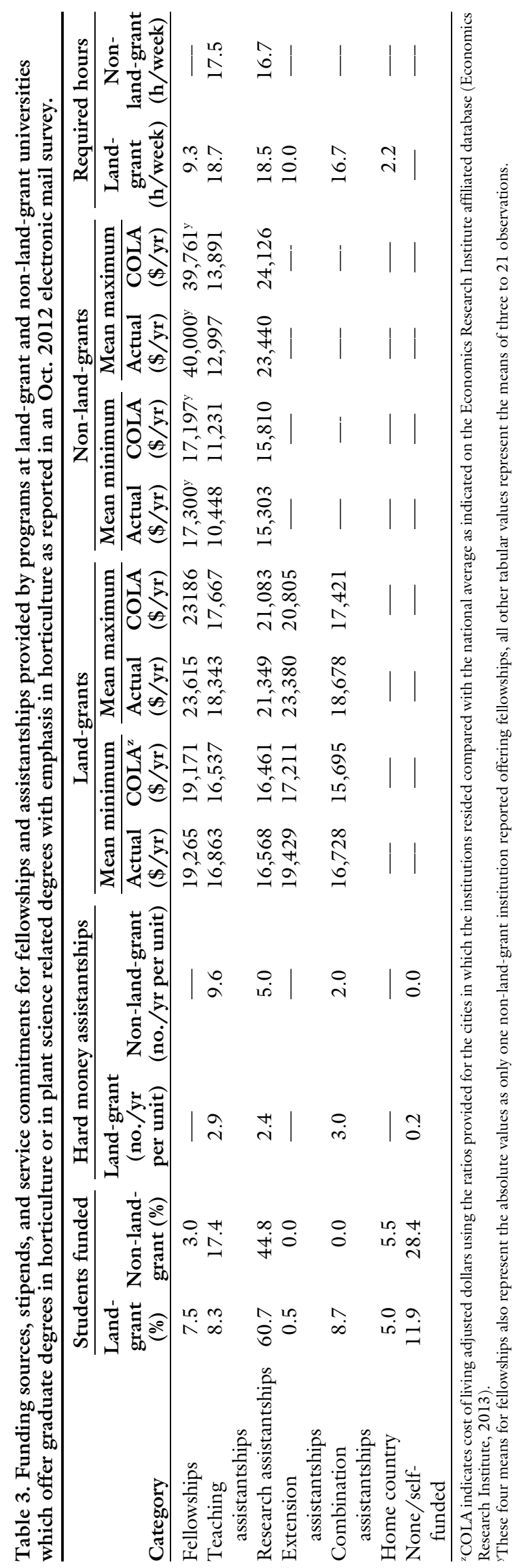


increased at NLG compared with 2005, but decreased for LG over the same time span (Arnold et al., 2006).

Mean fellowship stipends at LG ranged from a mean minimum of $\$ 19,265$ to a mean maximum of $\$ 23,615$. These stipends have increased substantially (previously $\$ 14,756$ mean minimum, $\$ 20,042$ mean maximum) in comparison with those offered by both types of schools in 2005 (Arnold et al., 2006). The greater value of fellowships is not surprising as they are frequently used to lure top candidates to the graduate student positions. Absolute minimum/ maximum ranges for fellowship stipends were from $\$ 1100$ (\$1149 COLA) to $\$ 40,000$ ( $\$ 40,040$ COLA) encompassing the widest range of variation in stipends for any of the sources of funding. Research assistantship stipends had an absolute range of $\$ 4368$ ( $\$ 4329$ COLA) to $\$ 31,000(\$ 30,815$ COLA) per year, while teaching stipends had an absolute range of $\$ 6825$ (\$7051 COLA) to $\$ 26,700$ ( $\$ 20,015$ COLA). Increases in both mean minimum and mean maximum research assistantships $(12.0 \%$ to $67.4 \%)$ far outpaced increases in mean minimum and mean maximum teaching assistantships $(9.0 \%$ to $15.8 \%$ ) at both types of institutions since 2005 (Arnold et al., 2006). The range of reported dollars for a teaching assistantship illustrates the importance of graduate students considering the cost of living when choosing a graduate program. As previously indicated, the greatest absolute dollar amount of a teaching assistantship was reported as $\$ 26,700$, but the high cost of living associated with the location resulted in a COLA stipend of only $\$ 20,015$. The second greatest reported teaching assistantship was slightly less at $\$ 26,000$ but was at a location with lower than average cost of living resulting in a COLA stipend of $\$ 26,860$. Hence, the lower actual stipend was the much better COLA stipend from an economic perspective. Assistantship stipends typically ranged at LG from a mean minimum research stipend of $\$ 16,568$ to a mean maximum extension assistantship stipend of $\$ 23,380$ (Table 3). The lowest absolute minimum research assistantship offered was $\$ 4368$ (\$4329 COLA), while the absolute greatest was $\$ 26,700$ ( $\$ 20,015$ COLA). NonLG offered substantially lower mean minimum assistantship stipends in teaching and research, especially with teaching assistantships (Table 3 ). Time commitments for fellowships were lower than for most assistantship classes, with most assistantships requiring in the range of $10 \mathrm{~h}$ to $20 \mathrm{~h}$ of service per week (Table 3 ).

Remuneration in the form of stipends was offered by $95.5 \%$ of LG programs and $80.0 \%$ of NLG programs. In addition, $95.5 \%$ of LG programs provided out-of-state tuition waivers, with $60.0 \%$ of NLG programs following suit. A vast majority $(90.9 \%)$ of LG programs offered instate tuition waivers, whereas only a minority $(40.0 \%)$ of NLG programs offered in-state tuition waivers. Most (59.1\%) LG programs offered medical insurance, but only $20.0 \%$ of NLG programs provided it. Only a few LG (13.6\%) or NLG $(20.0 \%)$ institutions paid student fees. Other forms of remuneration, such as funded travel or moving expenses, etc., were provided by $4.5 \%$ of LG programs, but no NLG programs offered additional benefits.

Mean yearly costs of in-state tuition were similar at LG $(\$ 10,227$ actual, \$9738 COLA) compared with NLG (\$10,103 actual, \$10,798 COLA). However, out-of-state tuition was on average considerably greater (\$18,964 actual, $\$ 18,630$ COLA) at LG than at NLG $(\$ 15,204$ actual, $\$ 16,327$ COLA). It is noteworthy to consider that for the majority of schools offering out-of-state and instate tuition waivers, this may nearly double the cost of funding a student compared with the actual amount of the stipend. Compared with 2005 (Arnold et al., 2006) at reporting LG in-state tuition, rates have risen on average $24.0 \%$, while those at reporting NLG rose $100 \%$. Along with the cost of health insurance, social security, etc., the cost of an assistantship can easily be $\$ 30,000$ or more per year to the unit or principal investigator. Considering a mean stay of 3.9 years (with prior M.S.) to 4.6 years (without prior M.S.) for LG Ph.D. students, these numbers can easily translate into an investment of well over a $\$ 100,000$ in direct salary and benefits alone for a single Ph.D. student, not including the costs of actually conducting research, tuition, fees, travel to meetings for presentations, etc. One phenomenon this has created is that it may be more cost effective to hire a technician or post doc than to hire graduate students. Darnell and Cheek (2005) expressed concerns that this shift was occurring in plant sciences in general as the shift of assistantship costs were transferred from the institution to individual faculty-supported funds. In this survey, Ph.D. programs at NLG took similar 3.5 years (with a prior M.S.) and 5.0 years (without a prior M.S.) time frames, respectively, as at LG. M.S. degrees took a mean of 2.4 years at LG and 2.1 years at NLG. Times were nearly reversed for nonthesis masters programs at LG, which were completed more quickly, with a mean of 2.1 years, while at NLG non-thesis masters programs took 2.5 years.

Course requirements and EXPERIENTIAL LEARNING IN HORTICULTURE GRADUATE DEgREE OR CONCENTRATION PROGRAMS. Total course and credit hour requirements were slightly greater at LG for horticulture concentrations within a plant science program than in horticultureonly degree programs; however, minimum research hour requirements were slightly greater in the Ph.D. in horticulture programs (Table 4). Ph.D. programs at NLG required on average fewer total credit hours and fewer research/internship hours, but far more formal course work hours (Table 4). Requirements were surprisingly uniform among thesis requiring M.S. in horticulture and M.S. in plant science with emphasis in horticulture programs, varying only slightly in requirements within a given category of courses (Table 4). A similar degree of uniformity was present for most categories of requirements for non-thesis masters programs, with the exception of research or internship hours that were much greater in LG than in NLG non-thesis masters programs in plant science with a horticulture concentration (Table 4 ). When available, online degrees were reported by all institutions to have the same credit hour requirements as inresidence degrees.

The surveyed institutions were asked to indicate whether additional experiences beyond normal classes were required in areas other than research, specifically teaching, extension/outreach, internships, or other. Teaching experiences were the only 
experiential learning requirement for most horticulture graduate degrees outside of the typical research experiences and were limited largely to
Ph.D. in horticulture and M.S. in horticulture programs at LG (Table 5). Teaching experience requirements were nearly identical to those reported

Table 4. Semester hour equivalent course requirements across doctor of philosophy (Ph.D.) and master of science (M.S.) graduate degree programs in horticulture or plant science related graduate degrees with horticultural emphasis areas among land-grant and non-land-grant institutions as reported in an Oct. 2012 electronic mail survey. ${ }^{2}$

\begin{tabular}{|c|c|c|c|}
\hline \multirow[b]{2}{*}{ Degree } & \multirow[b]{2}{*}{ Requirement } & \multicolumn{2}{|c|}{ Programs } \\
\hline & & $\frac{\text { Land-grant }}{(\mathrm{h})}$ & $\frac{\text { Non-land-grant }}{(\mathrm{h})}$ \\
\hline \multirow[t]{3}{*}{ Ph.D. Horticulture } & Total & 66.5 & - \\
\hline & Formal courses & 28.5 & - \\
\hline & Research/internship & 28.0 & - \\
\hline \multirow[t]{3}{*}{ Ph.D. Plant Science } & Total & 73.8 & 60.0 \\
\hline & Formal courses & 37.3 & 51.0 \\
\hline & Research/internship & 26.4 & 9.0 \\
\hline \multirow[t]{3}{*}{ M.S. Hort. (thesis) } & Total & 30.1 & 34.5 \\
\hline & Formal courses & 20.6 & 24.0 \\
\hline & Research/internship & 7.8 & 9.0 \\
\hline \multirow[t]{3}{*}{ M.S. Plant Science (thesis) } & Total & 30.2 & 33.0 \\
\hline & Formal courses & 19.4 & 23.5 \\
\hline & Research/internship & 8.1 & 9.5 \\
\hline \multirow[t]{3}{*}{ M.S. Hort. (non-thesis) } & Total & 32.3 & 36.5 \\
\hline & Formal courses & 29.3 & 32.0 \\
\hline & Research/internship & 3.0 & 4.3 \\
\hline \multirow[t]{3}{*}{ M.S. Plant Science (non-thesis) } & Total & 33.0 & 36.5 \\
\hline & Formal courses & 29.0 & 36.0 \\
\hline & Research/internship & 7.7 & 0.0 \\
\hline
\end{tabular}

${ }^{\mathrm{z}}$ All values are converted to semester hours. The total hours for Ph.D. programs represent the required number presuming the student already holds a masters degree. Note that formal courses and research/internship hours do not equal the total hours as these represent minimum requirements in those areas and some programs leave a large proportion of the credit hours flexible at the graduate committee's discretion. Where online degrees were available, institutions reported that online degrees had the same requirements for credit hours as in-residence programs.

in 2005 (Arnold et al., 2006). Davies (2005) also reported that little training was required to develop teaching or extension skills in LG horticulture graduate programs, and suggested that this may be due to an unwillingness of advisors to trade progress on graduate student research for teaching experience in our highly research-driven LG systems. Aside from teaching experiences, only internships in M.S. non-thesis programs at LG were required by more than $10 \%$ of the programs as additional experiential learning requirements among horticulture graduate programs (Table 5).

STUDENT EMPLOYMENT AND E N R O L L M E N T TRE N D S I N HORTICULTURE GRADUATE DEGREE OR CONCENTRATION PROGRAMS. Institutions were aware of the fields of employment of about two-thirds to three-fourths of their students over the past 10 years (Table 6). Academia was the most frequent field of employment for Ph.D. graduates from LG, whereas Ph.D. graduates from NLG and masters alumni from both LG and NLG programs were most frequently employed in industry (Table 6). Government positions were the third most frequently cited employment for both masters and Ph.D. graduates from LG, whereas government positions were the second most likely employment area for NLG graduates

Table 5. Experiential learning requirements for doctor of philosophy (Ph.D.) and master of science (M.S.) horticulture graduate programs beyond the normal research experiences required for thesis or dissertation based programs as reported in an Oct. 2012 electronic survey of land-grant and non-land-grant institutions. ${ }^{2}$

\begin{tabular}{|c|c|c|c|c|c|c|}
\hline \multirow[b]{2}{*}{ Experience } & \multicolumn{2}{|c|}{ Ph.D. } & \multicolumn{2}{|c|}{ M.S. (thesis) } & \multicolumn{2}{|c|}{ M.S. (non-thesis) } \\
\hline & $\begin{array}{c}\text { Land-grant } \\
(\%)\end{array}$ & $\begin{array}{c}\text { Non-land-grant } \\
(\%)\end{array}$ & $\begin{array}{c}\text { Land-grant } \\
(\%)\end{array}$ & $\begin{array}{c}\text { Non-land-grant } \\
(\%)\end{array}$ & $\begin{array}{c}\text { Land-grant } \\
(\%)\end{array}$ & $\begin{array}{c}\text { Non-land-grant } \\
(\%)\end{array}$ \\
\hline Extension & 9.1 & 0.0 & 9.1 & 0.0 & 4.5 & 0.0 \\
\hline Internship & 0.0 & 0.0 & 0.0 & 0.0 & 13.6 & 0.0 \\
\hline Other & 4.5 & 0.0 & 0.0 & 0.0 & 4.5 & 0.0 \\
\hline
\end{tabular}

${ }^{2}$ Values indicate the percentage of institutions requiring experiential learning in these areas in addition to basic course work or thesis/dissertation research.

Table 6. Students' post-graduate employment over the 10 years after graduation from masters or doctor of philosophy (Ph.D.) programs in horticultural areas from land-grant or non-land-grant institutions as reported in an Oct. 2012 electronic mail survey.

\begin{tabular}{|c|c|c|c|c|c|c|c|}
\hline \multirow[b]{2}{*}{ Institution type } & \multirow[b]{2}{*}{ Degree } & \multicolumn{6}{|c|}{ Proportion of students employed in: } \\
\hline & & $\begin{array}{c}\text { Academia } \\
(\%)\end{array}$ & $\begin{array}{c}\text { Government } \\
(\%)\end{array}$ & $\begin{array}{c}\text { Industry } \\
(\%)\end{array}$ & $\begin{array}{c}\text { Other } \\
(\%)\end{array}$ & $\begin{array}{c}\text { Unemployed } \\
(\%)\end{array}$ & $\begin{array}{c}\text { Unknown } \\
(\%)\end{array}$ \\
\hline & Ph.D. & 48.7 & 13.5 & 27.9 & 4.5 & 1.3 & 28.0 \\
\hline \multirow[t]{2}{*}{ Non-land-grant } & Masters & 5.0 & 25.0 & 63.3 & 5.0 & 0.0 & 26.3 \\
\hline & Ph.D. & 20.0 & 35.0 & 45.0 & 0.0 & 0.0 & 33.3 \\
\hline
\end{tabular}

${ }^{2}$ Values are within a category of institution type and degree program are mean percentages and may not total to $100 \%$ as all units did not respond to all questions. 
from both masters and Ph.D. programs (Table 6). "Other" was the lowest category except for the unemployment category for all degrees and was often cited to include positions such as those with nonprofit groups related to horticulture.

Enrollment in less than half of the LG horticulture Ph.D. programs and NLG horticulture masters programs remained steady and less than a quarter of the LG masters programs in horticulture reported steady enrollment (Table 7 ). Although a majority of programs experienced changes in enrollment, there was not a clear trend among these programs (Table 7). The LG Ph.D. horticulture programs reported mean decline levels that were very similar in magnitude to the increases reported by other programs (Table 7). For masters programs, the trend was for a greater mean percentage of decline at those institutions reporting downward enrollment than the percentage increases at institutions reporting upward enrollment trends (Table 7). When asked to forecast the adequacy of current enrollment to meet future needs for graduates, about half of the units thought that current enrollment levels were adequate to meet future demands for masters and Ph.D. programs in horticulture at LG and in masters programs at NLG (Table 7). For Ph.D. programs at LG and masters at NLG programs, the remaining respondents appeared to be about evenly split between current enrollment being insufficient and demand being unknown (Table 7). The general consensus among the remaining respondents for $L G$ masters programs in horticultural areas was that current enrollment numbers were insufficient to meet anticipated future demands (Table 7). Very few respondents felt that any of the programs were currently at excess levels for the anticipated future demands for graduates (Table 7).

GradUATE PROGRAM METRICS EMPLOYED IN EVALUATION OF HORTICULT URE DEGREE OR CONCENTRATION PROGRAMS. Increasing scrutiny of educational programs for accountability at all levels has led to strong motivations for the development of evaluative metrics to determine the efficacy of graduate programs in meeting institutional goals. A variety of metrics are being employed at various institutions and the emphasis placed on these metrics likely differs among institutions and perhaps over time within an institution. Ten metrics

Table 7. Enrollments in masters and doctor of philosophy (Ph.D.) programs in comparison with 5 years ago and the program administrators' perceptions of the adequacy of present enrollment levels to fill current demand as reported in an Oct. 2012 electronic mail survey of graduate programs in horticulture or related broader plant science programs with an emphasis in horticulture. ${ }^{\mathrm{z}}$

\begin{tabular}{|c|c|c|c|c|c|c|c|}
\hline \multirow[b]{2}{*}{ Degree } & \multicolumn{3}{|c|}{ Units' enrollment compared with 5 years ago } & \multicolumn{4}{|c|}{ Perception of units' present enrollments } \\
\hline & $\begin{array}{l}\text { Steady }^{y} \\
(\%)\end{array}$ & $\begin{array}{c}\text { Decline }^{x} \\
(\%)\end{array}$ & $\begin{array}{c}\text { Increase }^{x} \\
(\%)\end{array}$ & $\begin{array}{c}\text { Adequate }^{w} \\
(\%)\end{array}$ & $\begin{array}{c}\text { Insufficient }^{\mathrm{w}} \\
(\%)\end{array}$ & $\begin{array}{c}\text { Excess }^{\mathrm{w}} \\
(\%)\end{array}$ & $\begin{array}{c}\text { Unknown }^{\mathrm{w}} \\
(\%)\end{array}$ \\
\hline Masters & 22.7 & 39.0 & 20.6 & 59.1 & 40.9 & 0.0 & 9.1 \\
\hline Ph.D. & 40.9 & 30.6 & 26.9 & 50.0 & 22.7 & 4.5 & 22.7 \\
\hline \multicolumn{8}{|c|}{ Non-land-grant } \\
\hline
\end{tabular}

${ }^{2}$ Values within a category are mean percentages and may not total to $100 \%$ as all units did not respond to all questions.

'Within the column values represent the percentage of units responding that enrollment remained steady compared with 5 years ago.

'Within a column values indicate percentage of decline or increase compared with 5 years prior.

wThese categories represent the proportion of units reporting their perception of current enrollment as adequate, insufficient, excess, or unknown.

Table 8. Ranking of selected program metrics among land-grant programs and non-land-grant programs by which horticulture masters and doctor of philosophy (Ph.D.) graduate programs perceive themselves to be evaluated by their upper administration as reported in an Oct. 2012 electronic mail survey.

\begin{tabular}{|c|c|c|c|c|}
\hline \multirow[b]{2}{*}{ Metric } & \multicolumn{2}{|c|}{ Land-grants } & \multicolumn{2}{|c|}{ Non-land-grants } \\
\hline & $\begin{array}{c}\operatorname{Rank}^{\mathrm{z}} \\
(\text { mean })\end{array}$ & $\begin{array}{l}\text { Metric ranked in top } \\
\text { three by the unit }(\%)\end{array}$ & $\begin{array}{c}\operatorname{Rank}^{\mathrm{z}} \\
(\text { mean })\end{array}$ & $\begin{array}{l}\text { Metric ranked in top } \\
\text { three by the unit }{ }^{y}(\%)\end{array}$ \\
\hline Total number of graduate students & 4.2 & 90.9 & 4.3 & 100.0 \\
\hline Number of Ph.D. students & 3.5 & 77.3 & 1.7 & 20.0 \\
\hline Peer reviewed publications & 2.8 & 45.5 & 4.0 & 80.0 \\
\hline Student awards & 1.9 & 40.9 & 3.3 & 80.0 \\
\hline Graduate record examination scores & 0.9 & 13.6 & 1.8 & 60.0 \\
\hline Number of graduate courses taught & 0.8 & 9.1 & 3.3 & 60.0 \\
\hline Students involved in teaching & 0.7 & 9.1 & 2.0 & 60.0 \\
\hline Students' grade point ratio or average & 0.5 & 4.5 & 2.8 & 80.0 \\
\hline Other ${ }^{\mathrm{x}}$ & 1.2 & 18.2 & 0.0 & 0.0 \\
\hline
\end{tabular}

${ }^{z}$ Greater number within the column indicates greater importance in the metric. The highest ranked metric was keyed as a five to lowest ranked which was keyed in the analysis as a one. Unranked metrics were assigned a zero weight for that evaluator. The mean rank scores are presented.

"Values represent the mean percentage of the programs in which this metric was ranked within the top three metrics for their evaluation by upper administration.

"Graduation rates and time to degree were most frequently commented under "other." 
commonly mentioned in preliminary conversations were included in the survey (Table 8 ). A category of "other" with encouragement to write in the measure(s) not previously listed was also included.

Among LG, the highest ranked metrics by far were the "total number of graduate students enrolled in the program" and secondarily "the number of Ph.D. students enrolled" in the programs (Table 8 ). These measures were also the most frequent metrics to appear in the top three metrics for a given LG program (Table 8). Two measures of student's academic proficiency in the form of "student publication of peer reviewed publications" and "student awards" were the third and fourth ranked metrics, respectively, at LG programs (Table 8). These were also the next most frequently cited metrics in a given program's top three metrics (Table 8). The fifth and sixth highest ranked metrics were "other" and "course or student contact hours," respectively (Table 8 ). The two most frequently mentioned metrics under the "other" category by respondents that were not directly asked on the survey were "graduation rates or numbers" and "time to degree completion." All other measures were ranked of low importance on average and were included in less than $15 \%$ of the units surveyed top three metrics (Table 8 ). The relative importance of the various metrics seemed to be much more variable among institutions at NLG (Table 8 ). The number of Ph.D. students and "other" category were of much less importance to NLG than at LG programs (Table 8). Also, in contrast to LG programs, NLG placed a much higher rank on the number of graduate courses taught, students' involvement with teaching, students' grade point averages or grade point ratios, and GRE entrance scores (Table 8).

DEMOGRA P H I S A N D REMUNERATION OF FACULTY IN HORTICULTURE GRADUATE DEGREE OR CONCENTRATION PROGRAMS. Although departments were larger in LG than in NLG, the distribution of faculty among ranks was similar at both types of institutions (Table 9). The one difference was a slightly smaller proportion of professors at NLG and a bit greater proportion of lecturers (Table 9), but these differences were minor. The largest sector of faculty was Professors, with Associate Professors constituting the second largest proportion (Table 9). The typical faculty currently consists of 32.7 members at LG compared with 28.8 in 2005 , but was smaller at NLG with a current average of 21.2 members, which had shrunk compared with the 31.6 in 2005 (Arnold et al., 2006). Professorial rank faculty made up $95.4 \%$ of the faculty at LG. Most faculty were at mid- to-late career stages (Professor and Associate Professors). Early career stage faculty (Assistant Professors) consisted of only $18.3 \%$ to $18.9 \%$ of the faculty at LG and NLG, respectively. This suggests that in general the horticulture faculty is an aging population. Presuming a level or increasing number of positions in horticulture programs in the future, this would also suggest that there would be an increase in the demand for new Ph.D. students in the coming years as current faculty reach retirement.

Although graduate students were nearly evenly divided between males and females, faculty were still a majority male $(71.1 \%)$ while females $(28.9 \%)$

Table 9. Distribution of faculty by rank in North American land-grant and nonland-grant universities that offer graduate programs in horticulture or an emphasis in horticulture within broader plant science graduate programs as reported in an Oct. 2012 electronic mail survey.

\begin{tabular}{lccccc}
\hline & \multicolumn{2}{c}{ Land-grant } & & \multicolumn{2}{c}{ Non-land-grant } \\
\cline { 2 - 3 } \cline { 5 - 6 } Rank & $\begin{array}{c}\text { Faculty } \\
\text { (no./unit) }\end{array}$ & $\begin{array}{c}\text { Faculty } \\
\text { (percentage of } \\
\text { unit) }\end{array}$ & & $\begin{array}{c}\text { Faculty } \\
\text { (no./unit) }\end{array}$ & $\begin{array}{c}\text { Faculty } \\
\text { (percentage of } \\
\text { unit) }\end{array}$ \\
\hline Professor & 15.9 & 48.6 & & 9.3 & 43.9 \\
Associate Professor & 9.0 & 27.5 & & 6.3 & 28.3 \\
Assistant Professor & 6.3 & 18.3 & & 4.0 & 18.9 \\
Senior Lecturer & 1.0 & 3.1 & & 0.8 & 3.8 \\
Lecturer & 0.5 & 1.5 & & 0.8 & 3.8 \\
\hline
\end{tabular}

${ }^{2}$ Values within a column represent mean number of faculty at a given rank in a typical unit.

yalues within a column represent mean percentage of the total unit's faculty at a given rank. remained underrepresented in the faculty ranks. Unfortunately, the survey did not distinguish sex or ethnic differences with different ranks of faculty. Faculty members across ranks were predominantly non-Hispanic White $(84.9 \%)$. The largest minority group in the faculty ranks was Asian (8.5\%) followed by Hispanic (3.2\%). Pakistani/Indian (1.7\%), Black (0.9\%), Native American $(0.5 \%)$, and other $(0.2 \%)$ constituted very small portions of the faculty. Arabic, Nepalese, and Egyptian were specifically noted under the other category.

Most (66.5\%) of the horticulture faculty at LG are still in full year (11/12month) appointments, while slightly more than half $(54.3 \%)$ of faculty at NLG were in similar appointments. In comparison, full year appointments have declined since 2005 in frequency from the $79.3 \%$ at LG, but increased in percentage at NLG from $42.3 \%$ (Arnold et al., 2006). For LG, this was consistent with the FAEIS information (Marchant et al., 2010). Most of the remaining faculty members (19.3\% LG, $32.5 \%$ NLG) were in academic year (9/10-months) appointments with the opportunity to obtain external summer funding. A small proportion of the faculty members were in academic year appointments with internal sources of summer funding (4.0\% for LG and $13.2 \%$ for NLG programs). The remaining faculty were on academic year appointments with no options for summer funding internally or externally through the universities $(8.4 \%$ at LG units and $9.3 \%$ at NLG programs). Marchant et al. (2010) report that an increasing percentage of new hires are at 9-month or less appointments.

Mean salaries at horticulture or plant science programs with an emphasis in horticulture have risen for Professors (29.3\%), Associate Professors (24.3\%), Assistant Professors (27.5\%), Senior Lecturers (17.9\%), and Lecturers $(38.1 \%)$ compared with 2005 at LG, while salaries at NLG have risen $45.7 \%, 42.3 \%, 45.8 \%, 31.1 \%$, and $-54.4 \%$, respectively (Arnold et al., 2006). One of the most surprising changes in salary structures from the 2005 survey (Arnold et al., 2006) to present is that the salaries for senior faculty (Professors and Associate Professors) at NLG have gone from trailing those of their LG counter parts to surpassing them in the 
current survey (Table 10). Salary gains at NLG for those positions with professorial rank have outpaced gains at LG, while those lacking professorial rank have lagged behind at NLG. Interestingly, COLA salaries at participating LG tended to be lower than the actual reported dollar value, while COLA salaries at participating NLG tended to be greater than the nonadjusted salaries (Table 10). Salaries at the Assistant Professor level were similar at both types of institutions (Table 10). Salaries for lecturers at NLG lagged behind those of their LG counterparts, which were even more pronounced than in the 2005 survey (Arnold et al., 2006). While the sample size is fairly large for LG units (22), that of NLG is small (5) in this survey, and thus salary changes for NLG should be viewed with caution compared with the larger sample size for NLG units in the earlier 2005 survey.

Large salary variations appear to be a common occurrence with the most senior faculty, where the range of mean salaries is considerable (Table 10). Absolute minimum and maximum reported salaries for a professor at LG differed by $\$ 203,316$; even when placed on a COLA basis, the difference between the lowest and highest reported salaries was $\$ 167,743$ (Table 10). Considerable variation from least to greatest salaries was present in all categories of faculty, but none were as substantial in their variation as with senior faculty (Table 10). The variations in mean and mean maximum salaries are probably underestimates as several institutions indicated that the reported professor salaries did not include the unit head, typically the highest or one of the highest salaries in the unit. Such large variations in salary for similar appointments can be very detrimental to morale, contribute to job dissatisfaction, and increase turnover (Card et al., 2012).

Horticulture graduate degrees were more frequently offered at LG than at NLG units in comparison with broader plant science degree programs with an emphasis in horticulture, especially at the Ph.D. level. However, the mean number of students tended to be greater in the more generalized plant science degree programs. More students were funded in LG than NLG units. The majority of funded students were on research assistantships, with many schools indicating these were predominantly on external grants or faculty-derived funds. Mean stipends were considerably greater for research than teaching assistantships, especially at NLG units. Stipends for assistantships had increased considerably since 2005 . The data indicated the importance of considering a COLA analysis and benefits other than stipends when comparing graduate stipends offered by different universities. Admissions criteria and course work requirements tended to be uniform across institutions, particularly at LG programs. Aside from research requirements, experiential learning in graduate horticulture programs was minimal except for some limited participation in teaching experiences, which were mostly confined to Ph.D. and M.S. thesis programs at LG horticulture programs. The largest employment of horticulture Ph.D. graduates from LG was in academia and for NLG Ph.D. programs in industry positions. Masters graduates from both LG and NLG horticulture graduate programs were most likely to be employed in industry. Although variable among degree programs, the majority of program administrators indicated enrollment as steady or declined compared with 5 years ago, but also indicated that the perceived need for future enrollment was sufficient or insufficient to cover projected demand and almost none thought enrollment was in excess. This was consistent with preponderance of the faculty in horticulture programs being in senior professorial positions, which if positions are refilled suggest a need for more horticulture Ph.D. students in the future. Most categories of faculty salaries have increased since 2005, with the largest proportional gains being made among faculty at NLG. Faculty salaries were variable at all levels, but particularly so at the Professor level. Other than the total number of graduate students enrolled, metrics by which horticulture-oriented graduate programs were evaluated were extremely variable in importance among universities.

Table 10. Faculty salaries at land-grant and non-land-grant universities in units with horticulture degree programs as reported in an Oct. 2012 electronic mail survey. All salaries were asked to be submitted at a full-year 12-mo. basis for equal comparisons.

\begin{tabular}{|c|c|c|c|c|c|c|c|c|c|c|c|}
\hline \multirow[b]{2}{*}{ Institution } & \multirow[b]{2}{*}{ Rank } & \multicolumn{2}{|c|}{ Mean minimum ${ }^{\mathrm{z}}$} & \multicolumn{2}{|c|}{$\operatorname{Mean}^{\mathrm{z}}$} & \multicolumn{2}{|c|}{ Mean maximum $^{\mathrm{z}}$} & \multicolumn{2}{|c|}{$\begin{array}{l}\text { Absolute } \\
\text { minimum }\end{array}$} & \multicolumn{2}{|c|}{$\begin{array}{c}\text { Absolute } \\
\text { maximum }^{\mathrm{y}}\end{array}$} \\
\hline & & $\begin{array}{l}\text { Actual } \\
(\$ / y r)\end{array}$ & $\begin{array}{c}\text { COLA }^{\mathbf{x}} \\
(\$ / y r)\end{array}$ & $\begin{array}{l}\text { Actual } \\
(\$ / y r)\end{array}$ & $\begin{array}{c}\text { COLA }^{\mathbf{x}} \\
(\$ / y r)\end{array}$ & $\begin{array}{l}\text { Actual } \\
(\$ / y r)\end{array}$ & $\begin{array}{c}\text { COLA }^{x} \\
(\$ / y r)\end{array}$ & $\begin{array}{l}\text { Actual } \\
(\$ / y r)\end{array}$ & $\begin{array}{l}\text { COLA }^{\mathbf{x}} \\
(\$ / y r)\end{array}$ & $\begin{array}{l}\text { Actual } \\
(\$ / y r)\end{array}$ & $\begin{array}{c}\text { COLA }^{\mathbf{x}} \\
(\$ / y r)\end{array}$ \\
\hline \multirow[t]{5}{*}{ Land-grant } & rofes & 94,349 & 92,131 & 16,028 & 112,493 & 158,430 & 154,705 & 74,684 & 82,707 & 278,000 & 250,450 \\
\hline & Associz & 79 & 77,799 & 91,105 & 88,093 & 106 & 103,764 & 63,635 & 73,312 & 134,674 & 139,126 \\
\hline & Assistant I & 75,923 & 73,501 & 80,570 & 77,307 & 85,068 & 82,457 & 66,888 & 69,893 & 104,586 & 95,251 \\
\hline & Senior Lecturer & 69,337 & 75,064 & 75,030 & 81,136 & 80,722 & 87,208 & 55,609 & 50,646 & 103,000 & 118,664 \\
\hline & Lecturer & 50,283 & 52,826 & 53,280 & 54,012 & 64,580 & 67,341 & 39,000 & 35,747 & 128,062 & 130,012 \\
\hline \multirow{5}{*}{$\begin{array}{l}\text { Non-land- } \\
\text { grant }\end{array}$} & Professor & 109,196 & 115,045 & 117,426 & 124,547 & 150,087 & 158,469 & 97,920 & 110,644 & 169,847 & 168,834 \\
\hline & Associate I & 87,344 & 92,062 & 94,460 & 100,013 & 108,213 & 113,553 & 78,816 & 84,403 & 151,452 & 150,549 \\
\hline & Assistant Profess & 75,158 & 79,193 & 80,030 & 85,000 & 87,496 & 92,414 & 62,000 & 65,470 & 98,552 & 97,964 \\
\hline & Senior Lecturer & 46,079 & 48,713 & 46,079 & 48,703 & 46,079 & 48,713 & 42,000 & 44,351 & 50,157 & 53,076 \\
\hline & Lecturer & 18,135 & 20,075 & 26,458 & 29,480 & 33,750 & 37,719 & 11,250 & 11,880 & 56,250 & 59,973 \\
\hline
\end{tabular}

${ }^{\mathrm{z}}$ Mean salaries, and in particular mean maximum salaries, are probably under estimated for professors as several schools noted that their data did not include unit head or other administrators' salaries in their reported figures.

y Absolute lowest and highest salaries reported among all institutions for the indicated rank and institutional category.

${ }^{x}$ COLA indicates cost of living adjusted dollars using the ratios provided for the cities in which the institutions resided compared with the national average as indicated in the Economics Research Institute database (Economics Research Institute, 2013). 


\section{Literature cited}

Academic Analytics. 2013. Academic Analytics: Benchmarking for academic excellence. 21 Feb. 2013 . <http:// academicanalytics.com/Public/About>.

Arnold, M.A., T.D. Davis, and D.W. Reed. 2006. A survey of horticulture and plant science graduate programs and faculty salaries at North American universities. HortTechnology 16:146-152.

Astin, A.W. and A.L. Antonio. 2012. Assessment for excellence: The philosophy and practice of assessment and evaluation in higher education. 2 nd ed. Rowman and Littlefield Publ., Lanham, MD.

Beidler, K.M., J.K. Iles, S.M. Nusser, and A.M. VanDerZanden. 2006. Assessing the preparedness of postsecondary graduates entering the landscape contracting industry. HortTechnology 16:312317.

Card, D., A. Mas, E. Moretti, and E. Saez. 2012. Inequality at work: The effect of peer salaries on job satisfaction. Amer. Econ. Rev. 102:2981-3003.

Darnell, R.L. and J.G. Cheek. 2005. Plant science graduate students: Demographics, research areas, and recruitment issues. HortTechnology 15:677-681.

Davies, F.T. 2005. Graduate education in horticulture: Admissions, requirements, and success. Amer. Soc. Hort. Sci. Nwsl. 21(1):3-4.

Duncan, E., A.M. VanDerZanden, C. Haynes, and L. Esters. 2008. Curriculum evaluation: An outcomes assessment at the Department of Horticulture, Iowa State University. HortTechnology 18:524-528.

Economics Research Institute. 2013. Cost of living comparison calculators and data. 15 Dec. 2013. <http://www. costofliving.net $/$ index.cfm? Fuseaction= Home.Main>.

Food and Agricultural Education Information System. 2014. Food and agricultural education information system: Student enrollment in FAEIS. 5 Mar. 2014. <http:/www.faeis.ahnrit.vt.edu/ index.shtml>.

Madewell, T.M., M.C. Savin, and K.R. Brye. 2003. Alumni and employer perceptions of crop, soil, and environmental science curricula: Survey results. J. Nat. Resource Life Sci. Educ. 32:100-106.

Marchant, M.A., J.D. Hamm, T.P. Mack, J.R. Hunnings, W.W. Richardson, and H.D. Sutphin. 2010. The USDA's Food and Agricultural Education Information System: FAEIS. North Amer. Colleges Teachers Agr. J. 54(4):30-34.

Nichols, J.O. and K.O. Nichols. 2000. The departmental guide and record book for student outcomes assessment and institutional effectiveness. 3rd ed. Agathon Press, Edison, NJ.

Oltman, P.K. and R.T. Hartnett. 1984. The role of GRE general and subject test scores in graduate program admission. Graduate Record Examinations Board Res. Rpt. No. 81-8R, Educ. Testing Ser. Res. Rept. 84-14, Educ. Testing Service, Princeton, NJ.

Rom, C.R. 2004. Horticulture higher education for the 21 st century: The case of curriculum change and degree requirements at the University of Arkansas, USA. Acta Hort. 641:49-56.

University of Texas at Austin. 2011. Instructional assessment resources: Assess teaching response rates. 6 Mar. 2014. <http://www.utexas.edu/academic/ $\mathrm{ctl} /$ assessment/iar/teaching/gather/ method/survey-Response.php>.

U.S. Department of Education. 2014. The integrated postsecondary education data system (IPEDS): Classification of instructional programs (CIP). 6 Mar. 2014. <http://nces.ed.gov/ipeds/ cipcode $/$ Default .aspx?y=55 $>$.

VanDerZanden, A.M. and M. Reinert. 2009. Employer attitudes and perceptions of job preparedness of recent Iowa State University horticulture graduates. HortTechnology 19:647-652. 